\title{
AN-INVITRO COMPARISON OF THERMOCYCLING EFFECT ON MICRO- HARDNESS AND MICRO-TENSIL BOND STRENGTH OF NANO COMPOSITE DENTURE TEETH
}

\author{
Hala Mohamed Abd El Hameed*
}

\begin{abstract}
Purpose: The purpose of this study was an evaluation of the effect of thermocycling on microhardness and microtensile bond strength ( $\mu \mathrm{TBS}$ ) of the cross-linked acrylic and nanocomposite teeth to the acrylic denture base. Materials and methods: twelve teeth of the upper denture teeth were selected. Six teeth of nano-hybrid composite resin denture teeth and six cross-linkedacrylic teeth. These teeth, together with theacrylic resin bases, have been fixed to a micro- sawing machine to form 120 microbeam samples. These samples were divided into two storage regimes (dry and thermocycler), forming eight groups, each group containing 15 beams. These 8 groups were divided in equal parts to test the micro-hardness and strength of the micro-tensile bond (4 groups for each test).
\end{abstract}

Results: Paired t-test was used to analyze the effect of aging on micro- hardness and microtensile bond strength for both types of denture teeth. The tests were considered significant when $p$ $\leq 0.05$ and highly significant when $\mathrm{p} \leq 0.001$. Thermocycling procedure decrease the mean values in micro-tensile bond strength for both types of denture teeth brands but with statistical significant difference regarding the cross- linked acrylic one . it produces highly significant decrease in mean values for cross- linked acrylic but has nearly no effect on nanocomposit teeth regarding the microhardness test. Considering denture teeth brand Cross linked acrylic denture teeth showing higher mean values in micro- tensile bond strength before and after aging. Also, it was showing higher mean values in micro-hardness before thermocycling. This condition was totally reversed after aging as nano composite teeth showing higher mean values with significant difference in relation to acrylic one.

Conclusion: The newly introduced nanohybrid composite denture teethwere less markedly affected by thermocycling specially in term of hardness, but practically and from financial point of view, the cross- linked acrylic resin teeth has a comparable result to nanocompsite one as it shows higher micro-tensile bond strength ( $\mu$ TBS) so, it appears more applicable for patients.

KEYWORDS: Dentureteeth, denturebasematerials, microtensile bondstrength, microhardness; thermo-cycling

\footnotetext{
* Assistant Professor of Prosthodontics, Faculty of Dentistry Suez Canal University
} 


\section{INTRODUCTION}

Up to the present time debonding of acrylic denture teeth from their bases is a prevalent clinical apparition in prosthodontic practice embracing $22 \%$ to $30 \%$ of denture repairs. This condition increase in implant-supported dentures by the advancement of masticatory function. ${ }^{1}$ Prior studies documented that micro-tensile bond strength ( $\mu \mathrm{TBS}$ ), with diminutive testing surface area, will be more favorable in estimating bond strength of adhesive interfaces because of more regular interfacial stresses between different dental materials ${ }^{2}$

A direct relevance between hardness property to wear opposition and it is the vital mechanical property guide for restorative and artificial teeth materials. Abrasion of artificial teeth is of great interest for both patient and dentist. ${ }^{3}$

Hardness may have an endangering effect on occlusal vertical dimension, teeth relationship and functional efficiency of masticatory muscles. All these factors enhancing the horizontal stress on the masticatory system that led to altering the temporomandibular joint. Mouth environment, temperature, chemical structure and the kind of denture teeth materials are items that can impact the hardness of denture teeth. ${ }^{4}$

Submitting of Nano Hybrid Composite denture teeth in 2010 considered realre generation in the dental marketing. Nanocomposites were manufactured from homogenous urethane organic matrix reinforced by heterogeneous, pre-polymerized silica fillers. Nanocomposite denture teeth possess special characteristics in terms of homogeneity, the material are not cross-linked but contains nano-sized inorganic fillers that well dispersed in the resin matrix. ${ }^{5}$

Thermocycling is a simulating test based on intraoral temperature range changes that occur within normal food consumption activities with a higher range being $45-60{ }^{\circ} \mathrm{C}$ and lower range $4-15^{\circ} \mathrm{C}^{6.7}$
Theoretically, thermocycling allows for repeated expansion and contraction of the tooth and denture base components and stressing the bond. Another benefit of thermocycling was hydration of the specimens, thus imitating the clinical conditions. ${ }^{8}$ Therefore, the effect of thermo-cycling on micro hardness and micro tensile bond strength of nanohybrid composite denture teeth were estimated and matched with that of cross linked acrylic one.

\section{MATERIALS AND METHODS}

Sample preparation:Twelve maxillary anterior denture teeth were selected. Six nano-hybrid composite resin denture teeth (SR Phonares, Ivoclar Vivadent AG, USA) and six cross linked acrylic teeth (Acry Rock, Ruthinium, Italy). Molten wax was poured to fills quare shaped cavities within a silicone rubber mould frames then, the teeth were fixed to the molten wax (fig.1A).

After wax hardening the assembly including the wax with the denture teeth were detached from the silicon rubber base. The assembly were invested with dental stone (Acrostone.Egypt) into a dental flask (fig.1B). Heat polymerizable acrylic resin prepared by manufacturer recommendations (Acrostone. Egypy) and applied on the teeth in the space left after wax elimination (fig.1C-D).The resin polymerized by short cycle of hot water path at $74^{\circ} \mathrm{c}$ for 9 hours then at $100^{\circ} \mathrm{c}$ for one hour. The completed specimens were deflasked after polymerization and flask cooling. All specimens were stored at $37 \mathrm{C}$ for $50 \pm 2$ hs in distilled water. The processed specimens were introduced to a microw saw cutting machine for beams production. The specimens were fixed with cyanoacrylate glue to a metal base that was coupled to the cutting machine (Isomet 4000 microsaw Buehler USA) and sectioned under water cooling in $\mathrm{x}$ and $\mathrm{y}$ axes perpendicular to tooth -denture interface with slow speed diamond disk(fig.1E). Ten beam specimens were produced from each tooth (adhesive area $\pm 1 \mathrm{~mm}^{2}$, length \pm $8 \mathrm{~mm})($ fig.1F) . 


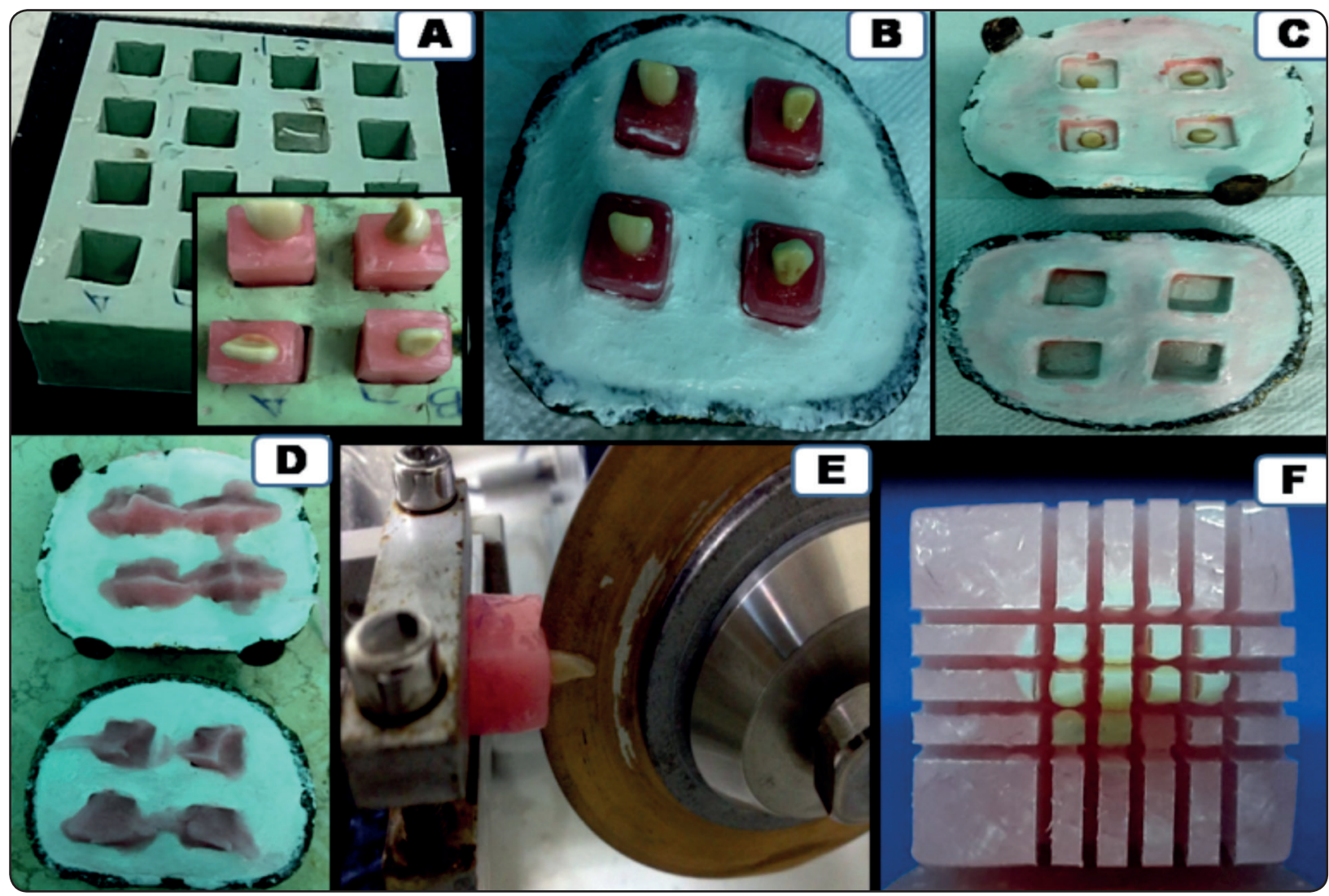

Fig. (1A) silicon frame with wax-tooth assembly, (fig.1B-D)processing of acrylic block to denture teeth, (fig.1E) sectioning toothacrylic block using cutting machine, (fig.1F)acrylic teeth beams

These beam specimens divided into two storage regimens (dry) before thermocycling and (thermocycled), forming eight groups each group contains 15 beams. These 8 groups divided equally for testing micro-hardness and micro-tensile bond strength (4 groups for each test) as follow: 30 dry beam specimens (15 beams from each type of denture teeth) and another 30 thermo-cycled beam specimens for micro-tensile bond strength test. The same was repeated for the other 4 groups for micro hardness test. Half of the specimens were thermo cycled by thermocycling device (THE-1100 SD Mechatroniks thermocycler, Germany) between $5^{\circ} \mathrm{C}$ (cold water path) and $55^{\circ} \mathrm{C}$ (hot water path) 30 second for each temperature and in 60-second for each cycle followed by 5 seconds rest before application of the next cycle for approximately5000 cycles(fig.2A).

\section{Micro-tensile bond strength ( $\mu$ TBS) test}

Half of the beam specimens tested by introducing them into the Instron Universal Testing machine (3345 model, England) that is controlled digitally and with a software for test control and information acquisition (Bluehill version 3.3). Fixation for each specimen was applied to metallic holding plate using cyanoacrylate adhesive. Tensile load (5000 $\mathrm{N})$ was applied at the ends of the beam specimens with a cross head speed of $0.5 \mathrm{~mm} / \mathrm{min}$ perpendicular to the tooth-denture base interface until debonding of the samples occurred. ${ }^{9}$ The bond strength $\left(\mathrm{kgf} / \mathrm{cm}^{2}\right)$ was calculated using the equation: $\mathrm{R}=$ $\mathrm{F} / \mathrm{A}$, where " $\mathrm{R}$ " is the $\mu \mathrm{TBS}$, "F" the load (Kgf) needed for specimen debonding, and " $\mathrm{A}$ " the interface area $\left(1 \mathrm{~mm}^{2}\right)$ of the specimens (fig.2B-C). 


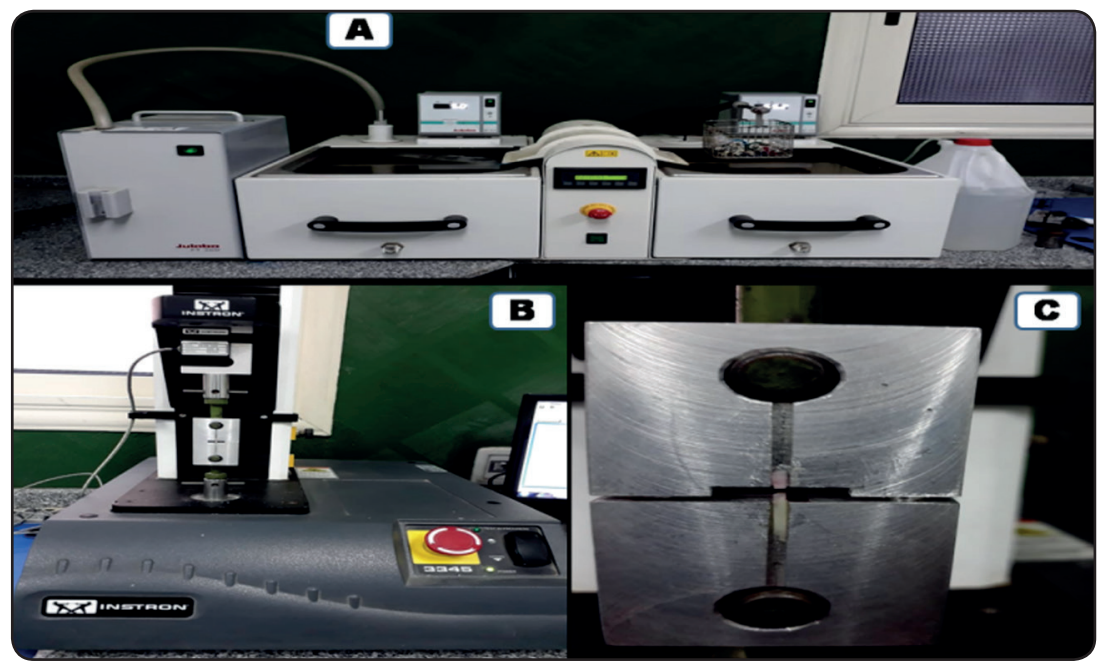

Fig. (2 A) thermocycler, (fig.2B) Instron Universal Testing machine, (fig.2C) debonding of the specimen after tensile load application

\section{Micro-hardness test}

In the Vickers hardness tester (Wilson Buehler micro-hardness, Germany), the (50 g/f) load was applied, without impact, forcing square base pyramid shaped diamond indenter into the test specimen. The indenter was held in place for 15 seconds (fig.3A-B). For getting accurate results, physical quality of the indenter and the accuracy of the applied load have been controlled. After load removal, focusing of the imprints by the magnifying eye piece and the two diagonals temperaments were estimated (fig.3C)., usually to the nearest $0.1-\mu \mathrm{m}$ with a filar micrometer, and averaged..$^{10}$ The Vickers hardness $(\mathrm{VH})$ is calculated by $\mathrm{VH}=1854.4 \mathrm{~L} / \mathrm{d}^{2}$ where the load $\mathrm{L}(\mathrm{gf})$ and the average diagonal $\mathrm{d}$ $(\mu \mathrm{m})$ (this produces hardness number units of $\mathrm{gf} /$ $\mu \mathrm{m}^{2}$. Mean values and standard deviations for each group and under each test were calculated and statistically analyzed.

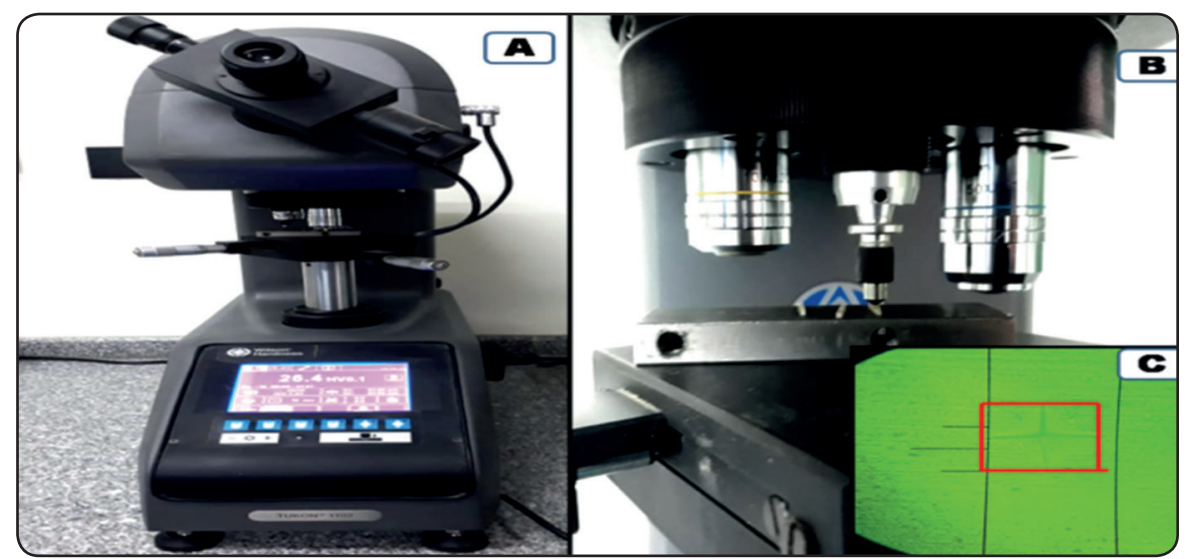

Fig. (3A) Vickers hardness tester, (fig.3B) indenter \& magnifying lens, (fig.3C) diagonal imprints image 


\section{RESULTS}

Data entry and analysis were performed using statistical software program. The quantitative data were presented as mean and standard deviations. Paired t-test was used to analyze the effect of thermocycling on micro hardness and micro-tensile bond strength for both types of denture teeth and to compare between different types of denture teeth through their mean values and the standard deviations. The significance level $(*)$ was set at $\mathrm{p}$ $\leq 0.05$, and highly significance level $(* *)$ was set at $\mathrm{p} \leq 0.001$

Thermocycling procedure decreased the mean values in micro- tensile bond strength for both types of denture teeth brands but with statistical significant difference $(\mathrm{P}=0.02)$ regarding the cross linked acrylic one (Table 1) .

Considering denture teeth, cross-linked acrylic one showed higher mean values in micro tensile bond strength before and after thermcycling but with significant difference $(\mathrm{P}=0.016)$ comparing to nano-hybrid composite teeth before thermocycling only (fig.43A)

Regarding the micro-hardness test thermocycling produced highly significant decrease in mean values for cross linked acrylic teeth $(\mathrm{P}=0.00)$ but has nearly no effect on nano-composit teeth regarding the micro-hardness test $(23.81 \pm 0.7 / 23.47 \pm 0.42)$.

Considering denture teeth brand Cross linked acrylic teeth showing higher mean values in micro hardness with highly significant difference ( $\mathrm{P}=0.000)$ comparing to nano-hybrid composite teeth before thermo-cycling. This condition was totally reversed after thermocycling as nano composite teeth showed higher mean values $(22.39 \pm 0.96 /$ $23.47 \pm 0.42$ ) (Table 2). with significant difference in relation to acrylic one(fig.43B). $(\mathrm{P}=0.002)$

TABLE (1) T-test for comparing mean values in micro-tensile bond strength of different samples

\begin{tabular}{|l|c|c|c|}
\hline Groups & $\begin{array}{c}\text { (Micro-tensilebond strength) } \\
(X \pm S D) \mathrm{b} /(X \pm S D) \mathrm{a}\end{array}$ & t-value \\
\hline Acrylic before/Thermo-acrylic & $54.5 \pm 13.25 / 47.8 \pm 18.97$ & 2.51 & $0.02^{*}$ \\
\hline Nanocomposite befor/ Thermo-Nano composite & $48.5 \pm 4.78 / 42.1 \pm 15.57$ & 1.24 & 0.114 \\
\hline Acrylic/Nanocomposite before thermocyclic & $54.5 \pm 13.25 / 48.5 \pm 4.78$ & 2.46 & $0.016^{*}$ \\
\hline Thermo-acrylic/Thermo-Nano composite & $47.8 \pm 18.97 / 42.1 \pm 15.57$ & 0.74 & 0.235 \\
\hline
\end{tabular}

$X=$ mean

$S D=$ standard deviation

TABLE (2) T-test for comparing mean valuesin micro-hardness of different samplesbefore (b) and after thermocyclic (a)

\begin{tabular}{|l|c|c|c|}
\hline Groups & $\begin{array}{c}\text { (Micro-Hardness }) \\
(X \pm S D) \mathrm{b}(/ X \pm S D) \mathrm{a}\end{array}$ & t-value & $P$-value \\
\hline Acrylicbefore/Thermo-acrylic & $26.26 \pm 0.8 / 22.39 \pm 0.96$ & 8.57 & $0.000 * *$ \\
\hline Nanocomposite before /Thermo-Nano composite & $23.81 \pm 0.7 / 23.47 \pm 0.42$ & 0.605 & 0.276 \\
\hline Acrylic before/ Nano composite before & $26.26 \pm 0.8 / 23.81 \pm 0.97$ & 5.82 & $0.000^{* *}$ \\
\hline Thermo-acrylic/ Thermo-Nano composite & $22.39 \pm 0.96 / 23.47 \pm 0.42$ & 3.254 & $0.002^{*}$ \\
\hline
\end{tabular}




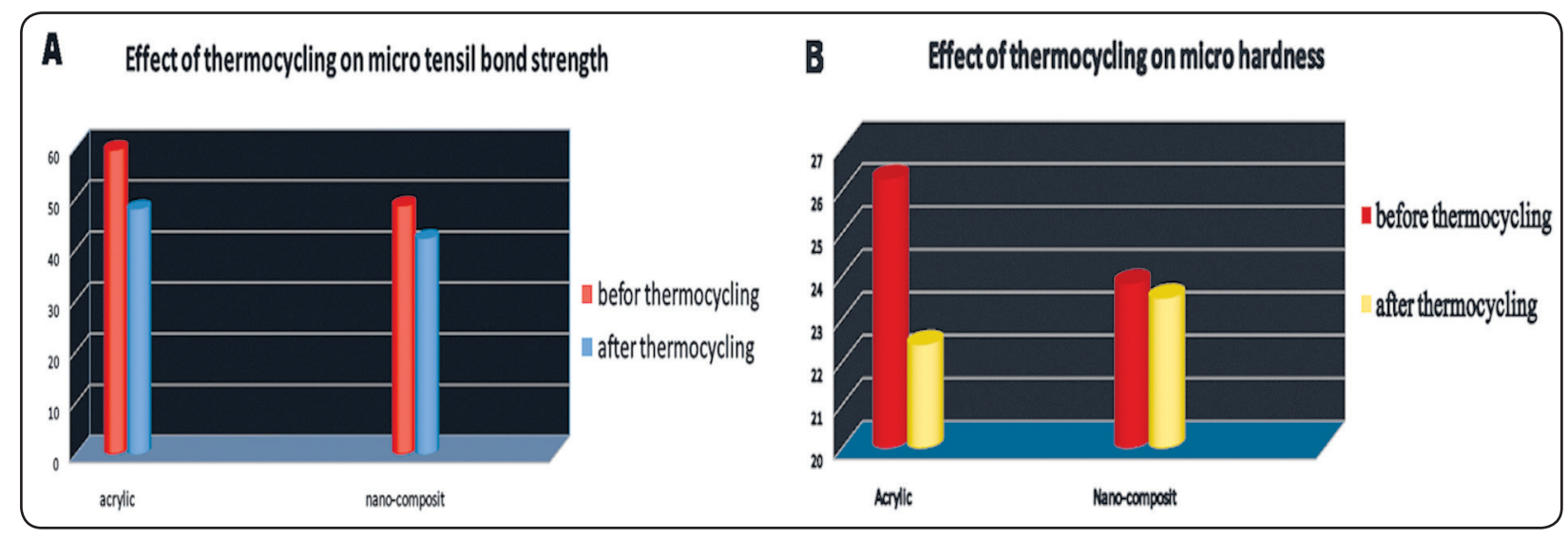

Fig. 4 (A\&B) histogram for the effect of thermocycling on microhardness \& microtensile bond strength

\section{DISCUSSION}

The separation of the teeth from the bases of the prosthesis is one of the essential clinical and laboratory challenges faced by the prosthetist, the technician and the patient. ${ }^{11}$

To overcome the disadvantages of acrylic resin teeth, cross-linking agents, different monomers and fillers have been added to their contents as a modification. $^{12}$

Micro-tensile( $\mu$ TBS) test is the first-selected method for estimating the bond strength of interfaces between different dental materials ${ }^{2}$

Micro-tensile bond strength ( $\mu$ TBS) test provides the ability to control the bonded surface area, allowing each specimen to have a more uniform distribution of interfacial stresses. ${ }^{13}$

Aging or thermocycling used as an in-vitro environment to generate thermal changes similar to the oral cavity. Simulating The normal temperature changes that human being can withstand .The basic idea of aging is periodic contraction and swelling creates stress inside the materials. Which will affects the longevity of the prosthesis service and deteriorates the bond between denture bases and teeth. ${ }^{14}$

Thermocycling gives rise to hydration of the samples, so the material imbibed water and this had a deleterious effect on the bonding. The water may diffused directly into the bond site, squashed in the voids at the interface leading to bulging and accordingly stresses originated at the tooth- denture base interface. ${ }^{15}$

The hardness of the material is the property which enables it to resist plastic deformation by penetration or indentation which results in an unknown increase in the depth of the impression during loading and the unknown amount of recovery of the indentation when the indenter is removed. ${ }^{16}$

Cross-linking the polymer chain that makes polymer molecules cannot slide over each other so easily decrease their flexibility and increase their hardness. This might explain higher micro-hardness mean value for Cross-linked acrylic denture teeth before thermocycling. ${ }^{17}$

The explanation for the decreased hardness after thermocycling is that the water has plasticizing effect. Considering small molecules of water diffuse into the polymer, progressively relaxing of the polymer chains and subsequently reduction of hardness of the acrylic resin denture teeth may occur. ${ }^{10} \mathrm{Also}$, it was reported that thermal stress caused by thermal cycling may generate microcracks formation inside the material leading to reduction of hardness. It was verified that temperature affects the characteristics of denture base materials. ${ }^{18}$

Nano-hybrid composite (NHC) material based on a urethane dimethacrylate matrix, which com- 
prises PMMA clusters as well as various types and sizes of filler (highly cross linked inorganic filled macrofiller, highly densified inorganic microfilled and silanized nanoscale filler based on silicon dioxide. $^{12}$

Chemical composition, size, shape and concentration of filler particles have significant effect on (NHC) prosperities. Macrofiller responsible for teeth strength. Size and quantity of inorganic micofiller enhance it's hardness and the resistance to thermocycling. ${ }^{10}$

\section{CONCLUSIONS}

- The newly introduced nano-hybrid composite denture teeth less markedly affected by thermocycling especially in term of microhardness, but practically and from a financial point of view, the cross-linked acrylic resin teeth has a comparable result to nanocomposite one as it shows higher ( $\mu$ TBS) so, it appears more applicable mainly for edentulous patients.

- It is recommended that another investigation of other characteristics for nanocomposite teeth should be performed under variable effects.

\section{REFERENCES}

1- Saavedra G, Valandro LF, Leite FPP, Amaral R, Ozcan M, Bottino MA. Bond strength of acrylic teeth to denture base resin aftervarious surface conditioning methods before and after thermocycling.Int J Prosthodont 2007;20:199-201.

2- Patil SB, Naveen BH, Patil NP.Bonding acrylic teeth to acrylic resin denture bases: a review. Gerodontology 2006; 23:131-139.

3- Suwannaroop P, Chaijareenont P, Koottathape N, Takahashi H, ArksornnukitM.: In vitro wear resistance, hardness and elastic modulus of artificial denture teeth. Dent Mater J.2011; 30(4):461-468.

4- Loyaga-Rendon PG, Takahashi H, Hayakawa I, Iwasaki N. : Compositional characteristics and hardness of acrylic and composite resin artificial teeth. J Prosthet Dent. 2007; 98(2): 141-149.

5- Kundu J, Kumar R, Seshan S.A study on evaluation of surface roughness and anti-staning propensity of nano- composite denture teeth. Int J Cur Res Rev.2014; 6(7): 52-57.
6- Adeyemi AA, Lyons MF, Cameron DA. The acrylic toothdenture base bond: effect of mechanical preparation and surface treatment. Eur J Prosthodont Res Dent.2007; 15:108-14.

7- Pande N, Zarekar S, Jaiswal P.Evaluation of shear bond strength of acrylic resin teeth to heat-polymerized denture base resin before and after thermocycling: An in vitro study.Indian J Multidiscip Dent 2018;8:25-32)

8- Hikmat JA,HusseinA A, Safi I N.Effect of surface treatments and thermocycling on shearbond strength of various artificial teeth with differentdenture base materials. J Bagh College Dentistry. 2013; 25: 5-13

9- Chaved C A, Regis R R, Machado A L, Souza R F.Effect of ridge lap surface treatment and thermocycling on microtensile bond strength of acrylic teeth to denture base resins. Braz Dent J .2009; 20: 127-131.

10- Assunça O W G, Ricardo Bara o V A, Delben J A. Effect of storage in artificial saliva and thermal cycling on Knoop hardness of resin denture teeth. J Prosthodont Res.2010;54: 123-127

11- Lang R, Kolbeck C, Bergmann R .Bond of acrylic teeth to different denture base resins after various surfaceconditioning methods.Clin Oral Investig. 2012;16:319-323

12- Priest G: Treatment of edentulous patients with SR Phonares ${ }^{\circledR}$. Int Dent SA .2010;13:70-76

13- Colebeck AC, Monaco EA,Pusateri CR, Davis EL. Microtensile Bond Strength of Different Acrylic Teeth to High-Impact Denture Base Resins. J of Prosthodont .2015; 24: $43-51$

14- Aljudy HJ, Hussein AN, Safi IN. Evaluation of Bond Strength of Surface Conditioned Artificial Teeth with Modified and Valplast Denture Bases With Aging. Iraqi Dent J. 2015; 37:97-106.

15- Marra J, Freitas de Souza R, Debora Barros Barbosa DB, Pero AC, Compagnoni MA.Evaluation of the bond strength of denture base resins to acrylic resin teeth: Effect of thermocycling. J of Prosthodont . 2009;18:438-443

16- Egilmeza F, Erguna G, Cekic-Nagasa I, Vallittub PK, Lassila LV. Does artificial aging affect mechanical properties of CAD/CAM composite materials. J Prosthodont Res.2018;62: 65-74

17- Yuzugullu B, Acar O, Cetinsahin C, Celik C .Effect of different denture cleansers on surface roughness and microhardness of artificial denture teeth.J Adv Prosthodont. 2016;8:333-833

18- Schneider RI; Curtis ER and Clancy JMS.Tensile bond strength of acrylic resin denture teeth to a microwave or heat processed denture base.J Prosthet Dent.2002; 88: 145-150. 